\title{
RTU3A-4
}

\section{A Miniature Low-Insertion-Loss, High-Power CMOS SPDT Switch Using Floating-Body Technique for 2.4- and 5.8-GHz Applications}

\author{
Mei-Chao Yeh, Ren-Chieh Liu, Zuo-Min Tsai and Huei Wang \\ Dept. of Electrical Engineering and Graduate Institute of Communication Engineering, \\ National Taiwan University, Taipei, 106, Taiwan, R.O.C.
}

\begin{abstract}
A low insertion loss SPDT switch in standard 0.18$\mu \mathrm{m}$ CMOS process was developed for 2.4- and 5.8-GHz WLAN applications. In order to reduce the insertion loss and increase the $P_{1 \mathrm{~dB}}$, the floating-body circuit topology is proposed. The series-shunt switch achieves a measured $P_{1 \mathrm{~dB}}$ of $20 \mathrm{dBm}$, an insertion loss of $1.1 \mathrm{~dB}$, and an isolation of $27 \mathrm{~dB}$ at $5.8 \mathrm{GHz}$. It also achieves a measured insertion loss of $0.65 \mathrm{~dB}$ and an isolation of $35 \mathrm{~dB}$ at $2.4 \mathrm{GHz}$. The effective chip size is only 0.03 $\mathrm{mm}^{2}$. The measured data agree with the simulation results well. To our knowledge, this work presents the low insertion loss, high isolation and good power performance with the smallest chip size among the previously reported $2.4-$ and $5.8-\mathrm{GHz}$ CMOS switches.

Index Terms - CMOS, SPDT switch, body floating.
\end{abstract}

\section{INTRODUCTION}

In recent years, wireless communication systems have undergone explosive growth that is largely unanticipated. Much of this growth has been in complementary metal-oxide semiconductor (CMOS) technology. CMOS technology has been able to meet the more stringent cost constraints inherent in these more diverse mainstream applications. The advantages of silicon CMOS technology for RF and microwave control functions over GaAs are its low cost structure and its integration potential with $R F$ and silicon MOS-based mixed-signal circuitry. A high-quality microwave switch is a key building block of a RF front end for timedivision duplexing (TDD) communication systems. To further increase the integration level, the SPDT switch has to be integrated in the transceiver.

Switches using high performance processes such as GaAs HEMTs were designed for digital mobile communication systems [1]. However, due to the advantages of low cost and integration capability with baseband circuits, the CMOS RF chips are getting more attractive. Key figures of merit of a T/R switch are insertion loss and power handling capability measured by the power $1-\mathrm{dB}$ compression point $\left(P_{\mathrm{IdB}}\right)[2]-[5]$. Switches using high and low substrate resistances in a 0.18 $\mu \mathrm{m}$ CMOS process have demonstrated good insertion loss [6], but it requires a large area of substrate contact to implement a low substrate resistance switch. To achieve such performance, a LC-tuned substrate bias was used [7]. However, the bias network improving the large-signal handling capability increased the chip size greatly. In the meanwhile, the LC. tuned substrate bias network limits the switch in a narrow frequency range. For $2.4-\mathrm{GHz}$ and 5.2-GHz applications, two different switches are designed and the LC-tuned substrate bias networks are needed to be devised respectively. Impedance matching technique was used to improve the $P_{\text {Id }}$ of the switch [8], but the matching network resulted in a large die size, also. Switch realized by depletion-layer-extended transistors (DETs) obtained high power-handling [9]. Nevertheless, the DETs are formed with the addition of more mask steps than the standard CMOS process, and in order to avoid latching up, the pMOS and $n$-well must be placed sufficiently far away from the DETs, and thus results in a large chip size.

In this paper, CMOS RF SPDT switches in standard 0.18$\mu \mathrm{m}$ CMOS process are presented. Using the body-floating technique, this approach demonstrates high power-handling with a miniature chip size. The SPDT switch exhibits $0.65-\mathrm{dB}$ insertion loss, $35-\mathrm{dB}$ isolation at $2.4 \mathrm{GHz}$ and $1 . \mathrm{I}-\mathrm{dB}$ insertion loss, 27-dB isolation, $20-\mathrm{dBm}$ output $P_{\mathrm{idB}}$ at $5.8 \mathrm{GHz}$. Table presents the recently reported performances of $5-6 \mathrm{GHz}$ CMOS switches. Compared with the CMOS switches at 5.8 $\mathrm{GHz}$, the chip accomplished the low insertion loss, high isolation, good power performance and smallest chip size simultaneously.

\section{BODY FLOATING TECHNIQUE}

The SPDT switch is fabricated in a $0.18-\mu \mathrm{m}$ CMOS process, which provides single poly layer for the gates of the MOS and six metal layers for inter-connection. As shown in Fig. 1, deep $n$-well (DNW) is offered as default in $0.18-\mu m$ mixed-signal process for better substrate isolation with an additional PN junction [10]. In this work, DNW is used to absolutely separate the body of the transistor with the p-substrate in the body-floating technique. Because of DNW, the switch can get rid of latching up.

The insertion loss of the switch was analyzed using the nMOS small signal model. As shown in Fig. $2, R_{\mathrm{B}}$ represents the substrate resistance associated with the transistor. $C_{\mathrm{T}}$ stands for the equivalent capacitance and can be represented as: 
TABLE I

RECENTLY REPORTED PERFORMANCE OF 5-6GHZ CMOS SWTTCHES.

\begin{tabular}{|c|c|c|c|c|c|c|c|}
\hline Process & $\begin{array}{c}\text { Frequency } \\
(\mathrm{GHz})\end{array}$ & $\begin{array}{l}\text { Insertion } \\
\text { loss (dB) }\end{array}$ & $\begin{array}{l}\text { Isolation } \\
\text { (dB) }\end{array}$ & $P_{1 \mathrm{dg}}(\mathrm{dBm})$ & $\begin{array}{c}\text { Effective } \\
\text { Chip Size } \\
\left(\mathrm{mm}^{2}\right)\end{array}$ & $\begin{array}{l}\text { Design } \\
\text { Features }\end{array}$ & Ref. \\
\hline $0.18-\mu \mathrm{m}$ CMOS & 5.8 & 0.8 & 30 & 17 & $0.21^{*}$ & $\begin{array}{l}\text { Low } \\
\text { substrate } \\
\text { resistance }\end{array}$ & [6] \\
\hline \multirow[t]{2}{*}{$0.18-\mu \mathrm{m}$ CMOS } & \multirow[t]{2}{*}{5.2} & $1.5(T x)$ & $30(T x)$ & $28(T x)$ & \multirow[t]{2}{*}{0.56} & \multirow{2}{*}{$\begin{array}{c}\text { LC-tuned } \\
\text { substrate } \\
\text { bias }\end{array}$} & \multirow[t]{2}{*}[7]{} \\
\hline & & $1.4(\mathrm{Rx})$ & $15(R x)$ & $12(R x)$ & & & \\
\hline \multirow[t]{2}{*}{$0.18-\mu \mathrm{m}$ CMOS } & \multirow[t]{2}{*}{5.0} & $0.95(T x)$ & $26.3(T x)$ & $22.7(T x)$ & \multirow[t]{2}{*}{$<0.1$} & \multirow{2}{*}{$\begin{array}{c}\text { Stacked } \\
\text { transistor } \\
\text { configuration } \\
\text { with DETs }\end{array}$} & \multirow[t]{2}{*}{ [9] } \\
\hline & & $1.44(R x)$ & $22.2(\mathrm{Rx})$ & $18.4(\mathrm{Rx})$ & & & \\
\hline $0.18-\mu \mathrm{m}$ CMOS & 5.8 & 1.1 & 27 & 20 & 0.03 & Body-floating & This Work \\
\hline
\end{tabular}

* Total chip size including pads.

$$
C_{\mathrm{T}}=C_{\mathrm{DB}}+C_{\mathrm{SB}}+\frac{\left(C_{\mathrm{GD}}+C_{\mathrm{GS}}\right) C_{\mathrm{GB}}}{C_{\mathrm{GD}}+C_{\mathrm{GS}}+C_{\mathrm{GB}}}
$$

From [2], the insertion loss and the isolation of the switch are determined by $C_{\mathrm{T}}$ and $R_{\mathrm{n}}$. The insertion loss is maximized when

$$
R_{\mathrm{B}(\max )}=\frac{1}{\omega_{C} \mathrm{~T}} .
$$

Usually, the value of $R_{\mathrm{B}}$ is close to $R_{\mathrm{B}(\max )}$ for transistors in the typical silicon processes which is not desired. To improve the insertion loss, the $R_{\mathrm{B}}$ should be either extremely large or close to zero. In fact, it is impossible to make $R_{\mathrm{B}}$ zero due to the parasitic effect, and thus how to let $R_{\mathrm{B}}$ be large enough is important. Furthermore, the parasitic capacitance associated with the body will seriously affect the impedance of the switch when the body of the transistor is connected to ground (RF short). Therefore, the body is connected to ground with 5$\mathrm{k} \Omega$ resistor as shown in Fig. 1. The resistor provides an open circuit for the RF signal to improve the insertion loss without affecting the impedance of the switch.

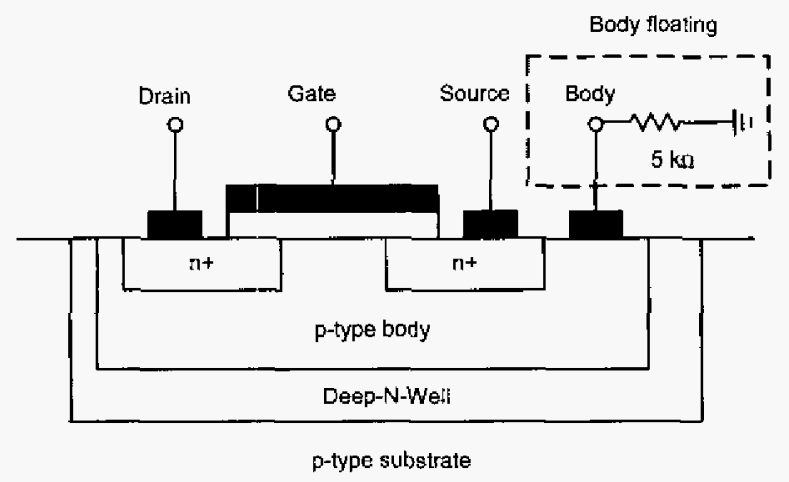

Fig. 1. A simple structure of DNW.

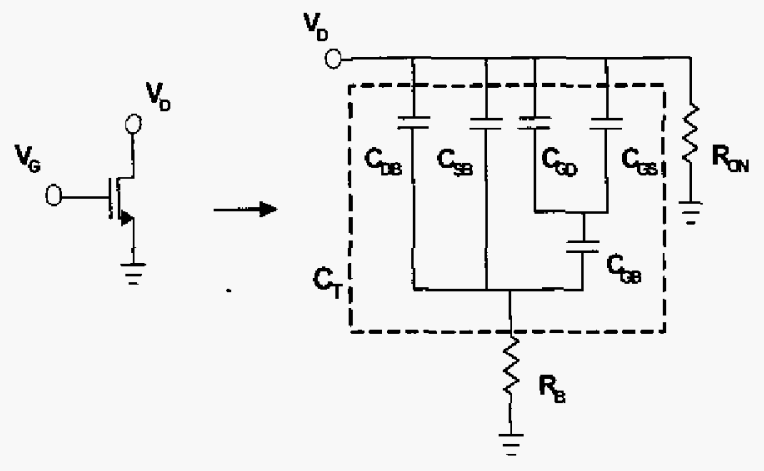

Fig. 2. Small signal model for a NMOS operating in the passive model,

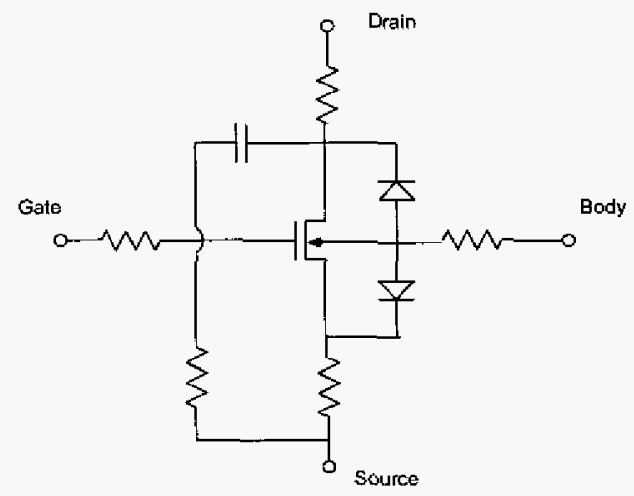

Fig. 3. Large-signal model of the device.

The body-floating technique also increases the power handling capability of the switch. Figure 3 shows the largesignal model of the device. In the on state, when the input power is high enough, the parasitic diodes between 
drain/source and body will turn on. The waveform of the input signal is then clamped, and the $P_{183}$ of the circuit will be limited. When the body of the device is floating, the parasitic diodes will not turn on even if the input power is high enough, and thus the $P_{\text {Id }}$ is improved. The simulated voltage waveforms of the output port of a $180-\mu \mathrm{m}$ series transistor are shown in Fig. 4, with the input power of $22 \mathrm{dBm}$. The difference between the peak values of the two different voltage waveforms is about $1.1 \mathrm{~V}$.

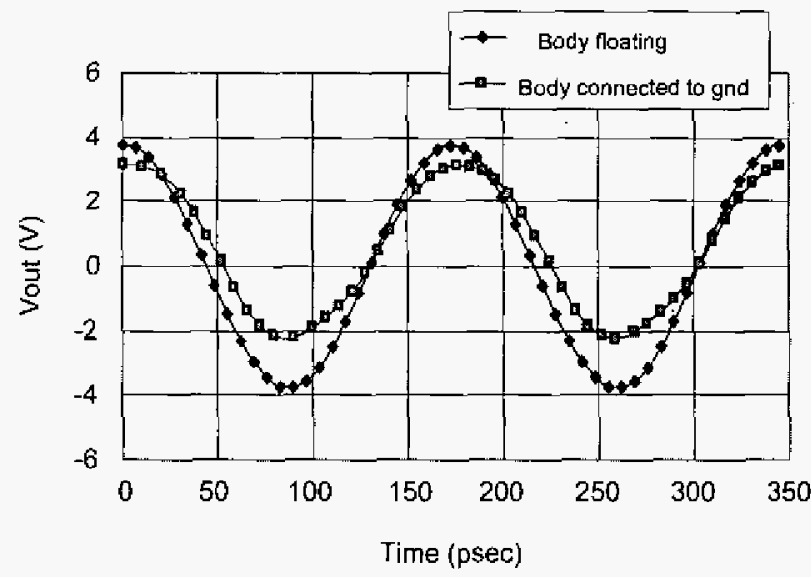

Fig. 4. Simulated voltage wayeforms of the output port in on-state transistor.

\section{CiRClitT Design}

By using body-floating technique, the insertion loss, isolation and power handling of the CMOS switch can be improved. Figure 5 is the schematic of the series-shunt CMOS RF SPDT switch which comprises two series and two shunt transistors. The series transistors $\mathrm{M} 1$ and $\mathrm{M} 2$ perform the main switching function, and the shunt transistors, M3 and M4, increase the isolation of the switch. It is observed that the ratio of the size for the series transistor to the shunt one significantly influence the performance of the switch, especially for the insertion loss. Figure 6 presents the simulated relation between the insertion loss and the gate width of series and shunt transistors. As can be observed, the size ratio of the series and shunt transistors must be selected properly. In order to achieve a low insertion loss, there are two choices: one is to use a large size for the series transistor and a small size for the shunt one, and the other is simply the opposite, that is, to choose a small size for the series device and a large size for the shunt one. The series transistor with larger size has smaller parasitic resistance and thus attains lower insertion loss and better power performance. For the concern of power handling capability, large devices of 180 $\mu \mathrm{m}$ gate width are chosen for series transistors $\mathrm{M} 1$ and $\mathrm{M} 2$ in this design while the size of shunt transistors M3 and M4 is 60 $\mu \mathrm{m}$. The gate bias resistors $R_{\mathrm{G} 1}, R_{\mathrm{G} 2}, R_{\mathrm{G} 3}$ and $R_{\mathrm{G} 4}$ are $.5 \mathrm{k}$ to improve the dc bias isolation.

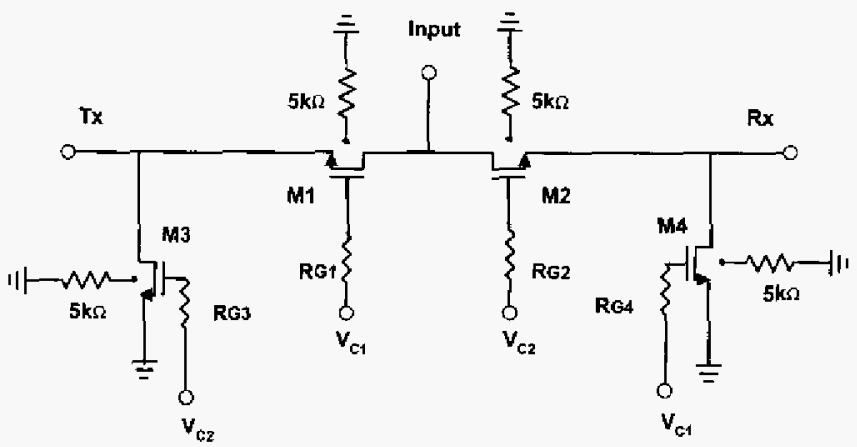

Fig. 5. Series-shunt switch schematic diagram.

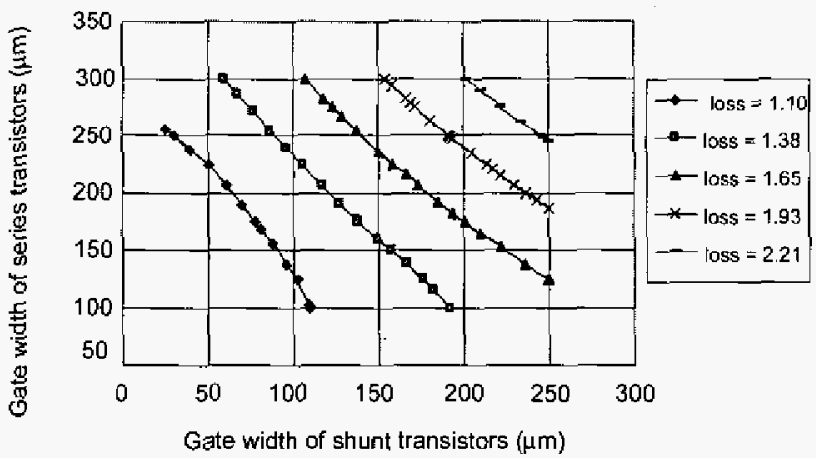

Fig. 6. The relationship between insertion loss and the sizes of the transistors. When the size ratio of the series and shunt transistors is chosen properly, the circuit has the lowest insertion loss.

\section{MEASUREMENT RESULTS}

The die micrograph of the series-shunt SPDT switch using $0.18-\mu \mathrm{m}$ CMOS process is shown in Fig. 7 . The chip size is $0.53 \times 0.37 \mathrm{~mm}^{2}$ and the effective circuit area without pads is only $0.2 \times 0.15 \mathrm{~mm}^{2}$. The circuit was tested via on-wafer probing. As shown in Fig. 8, the series-shunt switch achieves an insertion loss of $0.65 \mathrm{~dB}$ and an isolation of $35 \mathrm{~dB}$ at 2.4 $\mathrm{GHz}$. It also achieves an insertion loss of $1.1 \mathrm{~dB}$ and an isolation of $27 \mathrm{~dB}$ at $5.8 \mathrm{GHz}$. The measurements agree with the simulation results well. When the dc bias of the Tx and $\mathrm{Rx}$ nodes is $0 \mathrm{~V}, V_{\mathrm{C} 1}$ and $V_{\mathrm{C} 2}$ is 1.8 and $0 \mathrm{~V}$ respectively, the switch using $0.18-\mu \mathrm{m}$ device achieves a $P_{\text {lab }}$ of $20 \mathrm{dBm}$ at 5.8 $\mathrm{GHz}$ as shown in Fig. 9. Using devices of the same sizes, another SPDT switch without body-floating technique achieves a $P_{\mathrm{IdB}}$ of $18 \mathrm{dBm}$ at $5.8 \mathrm{GHz}$. The $P_{\mathrm{IdB}}$ of the switch is improved $2 \mathrm{~dB}$ by using the body-floating technique. 


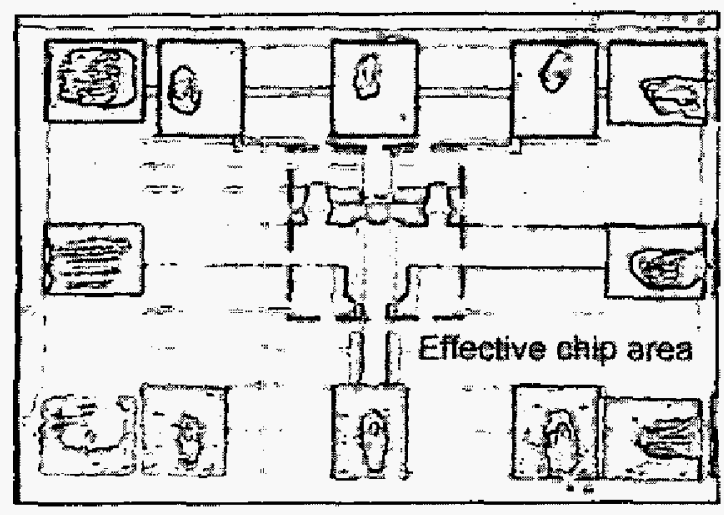

Fig. 7. Die photograph of $0.18-\mu \mathrm{m}$ CMOS switch. 'The effective circuit area without pads is only $0.03 \mathrm{~mm}^{2}$.

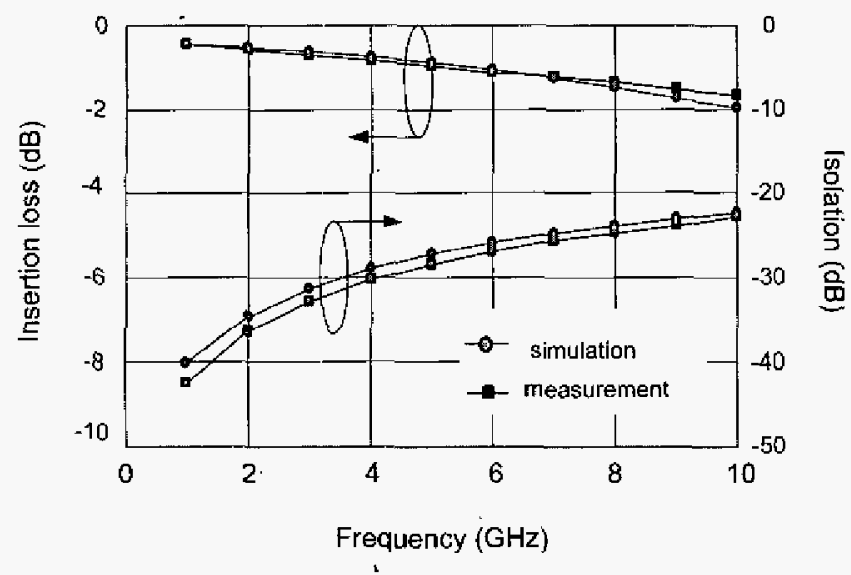

Fig. 8. Insertion loss and isolation of the $0.18-\mu \mathrm{m} \mathrm{CMOS} \mathrm{switch.} \mathrm{It}$ achieves a 1.1-dB insertion loss and 27-dB isolation at $5.8 \mathrm{GHz}$.

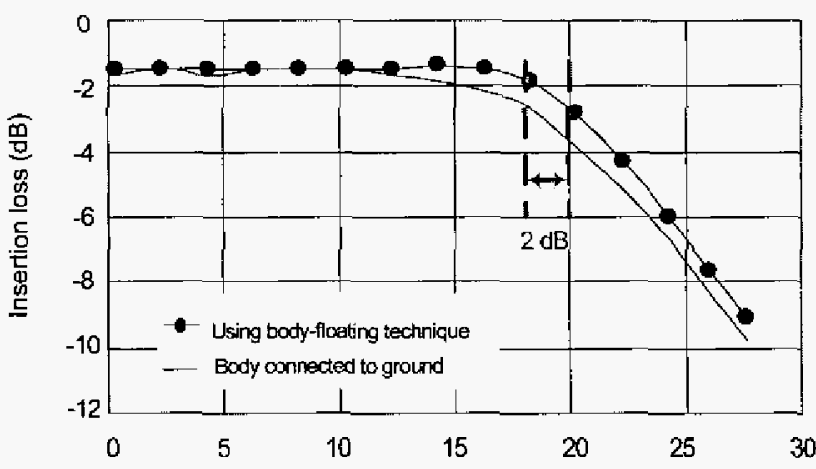

Fig. 9. Insertion loss v.s. $P_{\text {in }}$ of the $0.18-\mu$ m CMOS switch. Using the body-floating technique, the $P_{\mathrm{IAB}}$ of the switch is improved $2 \mathrm{~dB}$.

\section{CONCLUSION}

CMOS technology is a promising technology for RF and microwave control elements based upon the circuit model presented and on measurements in $0.18-\mu \mathrm{m}$ devices. A SPDT switch has been designed, fabricated, and tested. Using body floating technique, it accomplishes the low insertion loss, high isolation, good power performance and smallest chip size simultaneously. The switch exhibits 1.1-dB insertion loss, 27$\mathrm{dB}$ isolation, and $20-\mathrm{dBm}$ output $P_{\mathrm{ldB}}$ at $5.8 \mathrm{GHz}$. Since the switch was fabricated using standard $0.18-\mu \mathrm{m}$ CMOS technology, it can be easily integrated with other front-end circuits to implement CMOS transceivers without requiring any additional mask or post-processing steps.

\section{ACKNOWLEDGEMENT}

The work is supported in part by Sunplus and National Science Council of Taiwan R.O.C. (NSC 93-2752-E-002-002PAE, NSC 93-2219-E-002-016, NSC 93-2219-E-002-024 and NSC 93-2213-E-002-033).

\section{REFERENCES}

[1] K. Miyatsuji, S. Nagata, N. Yoshikawa, K. Miyanaga, Y. Ohishi, D. Ueda, "A GaAs high-power RF single-pole double-throw switch IC for digital mobile communication system," IEEE ISSCC1994 Dig. Tech. Papers, pp. 34-35.

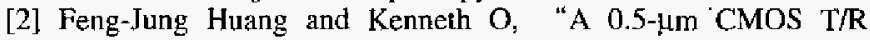
switch for $900-\mathrm{MHz}$ wireless applications," IEEE $J$. SolidState Circuits, vol. 36, pp. 486-492, May 2000.

[3] Aruna Ajjikuttira, Chester Lrung, Ee-Sze Khoo, Mark Choke, Rajinder Singh, "A fully-integrated CMOS RFIC bluetooth application," IEEE ISSCC2001 Dig. Tech. Papers, pp. 198-199.

[4] Kenneth K.O, Xi Li, Feng-Jung Huang, and William Foley, "CMOS components for $802.11 \mathrm{~b}$ wireless LAN applications," IEEE RFIC Symp., pp. 103-106, 2002.

[5] M. Madihian, L. Desclos, T. Drenski, "CMOS RF ICs for $900 \mathrm{MHz}-2.4 \mathrm{GHz}$ band wireless communication networks," IEEE RFIC Symp r, PF. 13-16, 1999.

[6] Zhenbiao Li, Hyun Yoon, Feng-Jung Huang, and Kenneth K. O, "5.8-GHz CMOS T/R switches with high and low substrate resistances in a $0.18-\mu \mathrm{m}$ CMOS process," IEEE Microwave Wireless Comp. Lett., vol. 13, Jan 2003.

[7] Niranjan Talwalkar, C Patrick Yue, and S. Simon Wong, "An integrated $5.2 \mathrm{GHz}$ CMOS T/R switch with LC-tuned substrate bias," IEEE ISSCC2003 Dig. Tech. Papers, pp. 362-363, 2003.

[8] Feng-Jung Huang, and Kenneth K. O, "Single-pole double-throw CMOS switches for $900-\mathrm{MHz}$ and $2.4-\mathrm{GHz}$ applications on $\mathrm{p}-$ silicon substrates," IEEE J. Solid-State Circuits, vol. 39, January 2004.

[9] Takahiro Ohnakado, Satoshi Yamakawa, Takaaki Murakami, Akihiko Furukawa, Eiji Taniguchi Hiro-omi Ueda, Noriharu Suematsu, and Tatsuo Oomori, "21.5-dBm power-handling 5$\mathrm{GHz}$ transmit/receive $\mathrm{CMOS}$ switch realized by voltage division effect of stacked transistor configuration with depletion-layerextended transistors (DETs)," IEEE J. Solid-State Circuits, vol. 39, January 2004.

[10] TSMC $0.18 \mu \mathrm{m}$ mixed signal $1 \mathrm{P} 6 \mathrm{M}+\mathrm{MIM}$ salicide $1.8 \mathrm{~V} / 3.3 \mathrm{~V}$ design guideline. 